\title{
STOCHASTIC INVENTORY CONTROL MODEL WITH TWO STAGES IN ORDERING PROCESS
}

\author{
Eugene Kopytov ${ }^{1}$, Leonid Greenglaz ${ }^{2}$ and Fedor Tissen ${ }^{1}$ \\ ${ }^{1}$ Transport and Telecommunication Institute, \\ 1 Lomonosova Str,LV-1019Riga,Latvia,E-mail: kopitov@tsi.lv/fedortissen@tsi.lv \\ ${ }^{2}$ Riga International School of Economics and Business Administration \\ 1 Meza Str, k. 2, LV-1048 Riga, Latvia, E-mail: gringlaz@,riceba.lv \\ Received 4 November 2005; accepted 14 December 2005
}

\begin{abstract}
The purpose of offered work is the construction of a stochastic single-product inventory control model for the chain "producer - wholesaler - customer". Given situation takes place in many transport and industrial companies. Criterion of optimization is minimum of average expenses for goods holding, ordering and losses from deficit per a time unit.
\end{abstract}

Keywords: inventory control, single-product order, demand, lead time, chain, optimization.

\section{Introduction}

It is quite complicate mathematical task to find the optimal solution for the necessary stock, if you are working in the transport or industrial company. The inventory control management model should take into account the random demand for the spare parts and consider the whole supply chain of the companies, which have influence on spare parts deliveries "manufacturer - supplier - intermediate company transport company". In practice it is common for inventory manager to answer on two basic questions: how much to order and when to order; and there are many different types of inventory control models which provide the decision-maker with a satisfactory solution (Prabhu 1967; Chopra and Meindl 2001; Greenglaz and Kopytov 2002; Ross 1992; Ryzhikov 2001).

In previous authors' works main attentions was devoted to economical aspects of inventory problem (Kopytov and Greenglaz, 2004; Kopytov et al., 2004; Ginevicius, 2004). We have to take into account that the sum of costs for goods ordering, holding and losses from deficit should be minimal. In the given paper authors suppose inventory model using the same economical criteria.

In the given paper we consider a stochastic singleproduct inventory control model for the chain "producer - wholesaler - customer". The wholesaler can use different ordering algorithms. The simplest algorithm considers the following situation: every customer's order is sent by wholesaler to producer at once and received goods are sent back to customers at once too. In the second variant wholesaler constructs a common order for group of customers taking in account or inventory level for each customer (using for example integrated database), or time of receiving the customers' orders and quantity of them. Finally we can consider third variant when the wholesaler has his owner storehouse with definite quantity of goods. There are other variants of ordering policy for wholesaler in practice, which will be considered in our further research.

\section{The formalization of the task}

In general there are two stages in the ordering process: 
- first stage executed by customer: in the moment of time, when the customer's stock level falls till certain level, a new order is sent to wholesaler;

- second stage executed by wholesaler: a new order is sent to producer. We have described different ordering algorithms executed by wholesaler in previous section. In general the ordering algorithm depends on following factors: total orders' quantity, number of actual orders, categories of customers and expected time of order delivery and others.

So, we consider the following chain "producer wholesaler - customer" with two stages in the ordering process shown in Fig 1.

In our research we examine two following situations:

1) every customer's order is sent by wholesaler to producer at once and received goods are sent back to customers at once too;

2) wholesaler constructs a common order for $m$ customers, after that this order is sent to producer; received goods are sent back to customers at once. Let note that some customers' orders are waiting the moment when then common order to producer will be created, as result the lead time for corresponding customers will increase. In given paper we suppose that $m=2$.

\section{Description of the model}

In practice of the inventory control the customer's demand for goods has mostly Poisson or normal distribution. Here we consider Poisson distribution using following conditions.

The demand for goods of customer with number $i$ is Poisson process with intensity $\lambda_{i}$. Time $L_{i}^{w, c}$ of goods delivery from wholesaler to $i$-th customer has normal distribution with parameters $\mu_{i}$ and $\sigma_{i}$ and time $L^{p, w}$ of goods delivery from producer to wholesaler has normal distribution with parameters $\mu_{0}$ and $\sigma_{0}$. Distribution of waiting time $L_{i}^{\text {wait }}$ from moment of order receiving from $i$-th customer till order sending to producer is determined by the ordering policy of

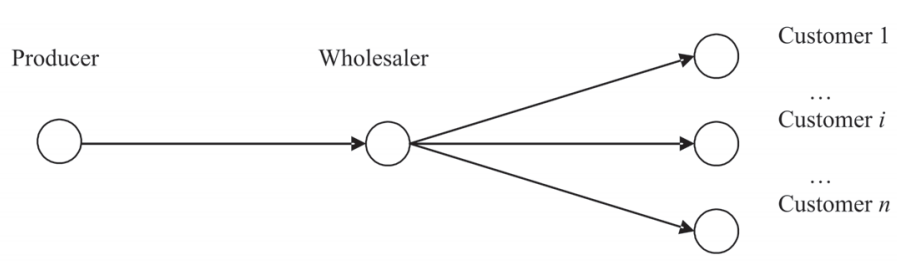

Fig 1. Chain of product ordering wholesaler. So, lead time (time between placing an order and receiving it) $L_{i}$ for $i$-th customer is

$$
L_{i}=L_{i}^{w, c}+L^{p, w}+L_{i}^{\text {wait }} .
$$

Ordering cost $C_{o}$ has two components: constant $c_{1}$, which includes cost of the order forming and constant part of expenses of order transportation, and variable component $c_{2}(q)$, which depends on the order quantity $q$. The policy of order forming for $i$-th customer is follows. A new order is placed in the moment of time, when the stock level falls till certain level $r_{i}$. The quantity $r_{i}$ is called as reorder point. The order quantity $q_{i}$ is constant. We suppose that $q_{i} \geq r_{i}$. We assume that for all customers holding cost is proportional to quantity of goods in stock and holding time with coefficient of proportionality $C_{H}$; losses from deficit are proportional to quantity of deficit with coefficient of proportionality $C_{S H}$.

Let's consider two situations described in section 2.

First situation. Every customer's order is sent by wholesaler to producer at once. So, $L_{i}^{\text {wait }}=0$ and we have

$$
L_{i}=L_{i}^{w, c}+L^{p, w} .
$$

Dynamics of inventory level of product for customer with number $i$ during one cycle (time interval between two subsequent order deliveries) is shown in Fig 2.

In given figure $Z_{i}$ is the quantity of product for $i$-th customer in stock in the time moment immediately after order receiving; $T_{i}^{0}$ is the time between receiving the order and placing a new order for $i$-th customer.

Using definitions given above we have the formula for length of cycle:

$$
T_{i}=T_{i}^{0}+L_{i}
$$

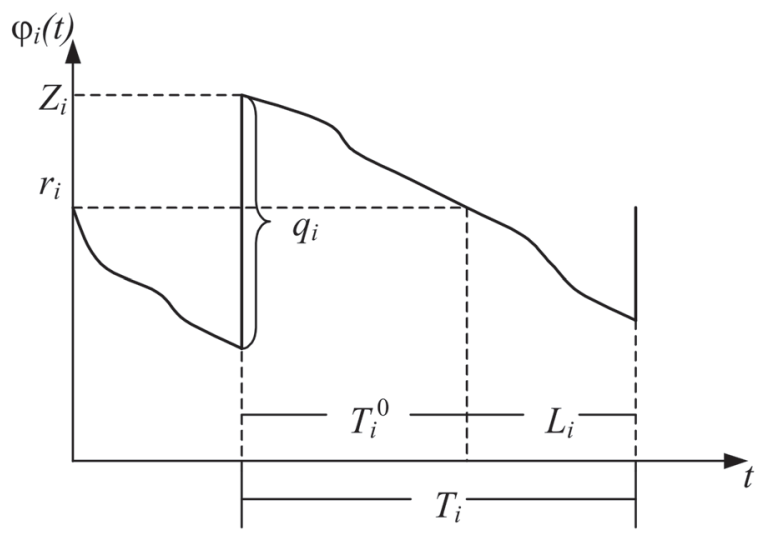

Fig 2. Dynamics of inventory level of product for $i$-th customer during one cycle 
Thus we can determine the quantity of goods $Z_{i}$ in stock in the time moment immediately after order receiving as function of demand $D_{L_{i}}$ during lead time $L_{i}$ :

$$
Z_{i}=\left\{\begin{array}{cc}
r_{i}+q_{i}-D_{L_{i}}, & D_{L_{i}}<r_{i} \\
q_{i}, & D_{L_{i}} \geq r_{i}
\end{array}\right.
$$

Based on the results of paper (Kopytov and Greenglaz 2004) we obtain the following formulas for $i$-th customer:

- distribution for quantity of goods $Z_{i}$ (see Figure 2) in stock in the moment immediately after order receiving

$$
\begin{aligned}
& P\left\{Z_{i}=j\right\}=P\left\{D_{L_{i}}=r_{i}+q_{i}-j\right\} \\
& =\frac{\lambda_{i}^{r_{i}+q_{i}-j}}{\left(r_{i}+q_{i}-j\right) ! \sigma_{L i} \sqrt{2 \pi}} \int_{0}^{\infty} \tau^{r_{i}+q_{i}-j} e^{-\lambda_{i} \tau} e^{-\frac{\left(\tau-\mu_{L_{i}}\right)^{2}}{2 \sigma_{L i}^{2}}} d \tau, \\
& q_{i}<j \leq q_{i}+r_{i} \\
& P\left\{Z_{i}=q_{i}\right\}=1-\sum_{j=q_{i}+1}^{q_{i}+r_{i}} P\left\{Z_{i}=j\right\},
\end{aligned}
$$

where $\mu_{L_{i}}=\mu_{i}+\mu_{0}, \sigma_{L i}^{2}=\sigma_{i}^{2}+\sigma_{0}^{2}$;

- average cycle time $T_{i}$

$E\left(T_{i}\right)=\sum_{j=r_{i}+1}^{q_{i}+r_{i}} P\left\{Z_{i}=j\right\} \frac{j-r_{i}}{\lambda_{i}}+E\left(L_{i}\right) ;$

- average holding cost $E\left(T C_{H_{i}}\right)$ within cycle $E\left(T C_{H i}\right)=$

$C_{H} \sum_{j=q_{i}}^{r_{i}+q_{i}} P\left\{Z_{i}=j\right\} \int_{0}^{\infty} \sum_{k=0}^{j_{i}-r_{i}} P\left\{D_{\tau}=k\right\} \cdot(j-k) d \tau+$

$C_{H} \int_{0}^{\infty}\left[\sum_{k=0}^{r_{i}} P\left\{D_{\tau}=k\right)\left(r_{i}-k\right)\right] P\left\{L_{i}>\tau\right\} d \tau$

- average shortage cost during lead time

$$
E\left(T C_{S H_{i}}\right)=C_{S H} \sum_{k=r_{i}+1}^{\infty} \frac{\lambda_{i}^{k}\left(k-r_{i}\right)}{k !} e^{-b_{i}} M_{k}\left(a_{i}, \sigma_{L_{i}}\right),
$$

where $M_{k}\left(a_{i}, \sigma_{L_{i}}\right)=\frac{1}{\sigma_{L i} \sqrt{2 \pi}} \int_{0}^{\infty} \tau^{k} e^{-\frac{\left(\tau-a_{i}\right)^{2}}{2 \sigma_{L_{i}}^{2}}} d \tau$;

$a_{i}=\mu_{i}-\lambda_{i} \cdot \sigma_{L_{i}}^{2} ; \quad b_{i}=\frac{\mu_{i}^{2}}{2 \sigma_{L_{i}}^{2}}-a_{i}^{2}$
- average total cost during time unit

$$
E(A C)=\sum_{i=1}^{n} \frac{E\left(T C_{i}\right)}{E\left(T_{i}\right)}
$$

where $E\left(T C_{i}\right)=C_{o}\left(q_{i}\right)+E\left(T C_{H_{i}}\right)+E\left(T C_{S H_{i}}\right)$, $E\left(T C_{H_{i}}\right), E\left(T C_{S H_{i}}\right)$ and $E\left(T_{i}\right)$ are defined accordingly by formulas (7), (8) and (6).

Second situation. The wholesaler forms the set of $m$ orders and after that it is sent to producer. Here we consider the case where $m=2$.

Let $T_{i}$ is the duration of a cycle for customer with number $i$ for $i=1,2$. Suppose that $E\left(T_{2}\right)>E\left(T_{1}\right)$, then $\Delta T=T_{2}-T_{1}$ is the waiting time of the first received order for the second order.

Then the lead time for given customers can be calculated by formulas

$$
\begin{aligned}
& L_{1}= \begin{cases}L_{1}^{w, c}+L^{p, w}, & \text { if } \Delta T \geq 0, \\
L_{1}^{w, c}+L^{p, w}+L^{\text {wait }}, & \text { if } \Delta T<0,\end{cases} \\
& L_{2}= \begin{cases}L_{2}^{w, c}+L^{p, w}, & \text { if } \Delta T \geq 0, \\
L_{2}^{w, c}+L^{p, w}+L^{\text {wait }}, & \text { if } \Delta T<0,\end{cases}
\end{aligned}
$$

where $L^{\text {wait }}=|\Delta T|$.

It is easy to see that the distribution of lead time $L_{i}$ for $i=1,2$ is not normal. Taking into account (10) we can write the formula for $L^{\text {wait }}$

$$
L^{\text {wait }}=|\Delta T|=\left|T_{2}-T_{1}\right| .
$$

Using formulas (3) and (10) we have

$$
\Delta T=T_{2}^{0}+L_{2}-T_{1}^{0}-L_{1}=T_{2}^{0}-T_{1}^{0}+L_{2}^{w, c}-L_{1}^{w, c},
$$

where $T_{i}^{0}$ has Erlang distribution and $L_{i}$ has normal distribution with their own parameters for $i=1,2$.

Hence, $T_{2}^{0}-T_{1}^{0}$ has Erlang distribution and $L_{2}^{w, c}-L_{1}^{w, c}$ has normal distribution. The distributions of lead time $L_{i}$ for, $i=1,2$ are defined by formulas (10) and (12).

Denote by $f_{L_{i}}(\tau)$ distribution of $L_{i}$, from (5) we obtain

$$
\begin{aligned}
& P\left\{Z_{i}=j\right\}=P\left\{D_{L_{i}}=r_{i}+q_{i}-j\right\}= \\
& \frac{\lambda^{r_{i}+q_{i}-j}}{\left(r_{i}+q_{i}-j\right) !} \int_{0}^{\infty} \tau^{r_{i}+q_{i}-j} e^{-\lambda_{i} \tau} f_{L_{i}}(\tau) d \tau, \quad q_{i}<j \leq q_{i}+r_{i} ;
\end{aligned}
$$




$$
P\left\{Z_{i}=q_{i}\right\}=1-\sum_{j=q_{i}+1}^{q_{i}+r_{i}} P\left\{Z_{i}=j\right\}
$$

Using (10), (12) and (13) we can create the mathematical model for given situation. In principle this task can be solve similar to the task considered above for the first situation, but in last case the analytical decision has some difficulties.

\section{Conclusions}

In this paper we have considered inventory control model for two stages in ordering process. We have examined two situations: every customer's order is sent by wholesaler to producer at once, a part of customers' orders are waiting the moment when integrated order will be created by wholesaler and send to producer. In the last situation we consider the case with two customers. Principal aim of proposed model is to define the exact order quantity and reorder point for each customer to achieve the minimum expenses for goods holding, ordering and losses from deficit per a time unit.

Further guidelines of the current research are the following: to consider the case with normal distribution of demand for goods and to investigate problem with $m>2$ customers in second situation. In is planed to We plan to examine suggested model in solving practical tasks for Latvian Railway company and to compare numerical results received using this model with the analogues results received by simulation.

\section{References}

Chopra, S. and P. Meindl. (2001). Supply Chain Management. Prentice Hall, London.

Greenglaz L., Kopytov E. (2002). Inventory Theory with Computer Examples: Study book. Riga: TTI, ECH, 91 p. (in Russian).

Ginevičius, R.; Korsakienè, R. (2004). The Influence of Marketing on Business: Theoretical and Practical Aspects. Business: Theory and Practice. Vilnius: Technika, Vol IV, No 3, p. 109-115.

Kopytov, E.; Greenglaz, L. (2004). On a task of optimal inventory control. In: Transactions of XXIV International Seminar on Stability Problems for Stochastic Models. September 10-17, 2004, Jurmala, Latvia. Riga: Transport and Telecommunication Institute, p. 247-252.

Kopytov, E.; Tissen, F. and Greenglaz, L. (2004). Inventory Control Model for the Typical Railways Company. In: Proceeding of the International Conference "RELIABILITY and STATISTICS in TRANSPORTATION and COMMUNICATION", Riga, Oct. 16-17, 2003). Transport and Telecommunication, Vol 5(1), p. 39-45.

Prabhu, N.U. (1967). Queues and Inventories. John Willey $\&$ Sons, New York.

Ross, Sh.M. (1992). Applied Probability Models with Optimization Applications. Dover Publications, INC., New York.

Ryzhikov J. (2001). Queues Theory and Inventory Control. Piter, St Petersburg (in Russian). 